\title{
Significance of Coronary Artery Disease and Left Ventricular Afterload in Unoperated Asymptomatic Aortic Stenosis
}

\author{
Kentaro Shibayama, MD; Masao Daimon, MD; Hiroyuki Watanabe, MD; Takayuki Kawata, MD; \\ Sakiko Miyazaki, MD; Ryoko Morimoto-Ichikawa, MD; Masaki Maruyama, MD; \\ Shuo-Ju Chiang, MD; Katsumi Miyauchi, MD; Hiroyuki Daida, MD
}

\begin{abstract}
Background: Because the covariates of cardiovascular events in unoperated patients with asymptomatic aortic stenosis (AS) have not been adequately evaluated, we aimed to identify them.

Methods and Results: A total of 230 patients with asymptomatic severe AS were retrospectively enrolled. The patients were divided into 2 groups based on aortic valve replacement (AVR) after enrollment: a non-AVR group $(n=112)$, and an AVR group $(n=118)$. The primary clinical endpoint was cardiovascular events, which were defined as cardiovascular death or hospitalization. Coronary artery disease [hazard ratio (HR): 3.62, 95\% confidence interval $(\mathrm{Cl})$ : 1.585-8.245, $\mathrm{P}<0.01$ ] and high valvulo-arterial impedance (HR: 3.08, 95\% Cl: 1.261-7.532, $\mathrm{P}<0.05)$ were identified as independent covariates of cardiovascular events in the non-AVR group. The relative risk of cardiovascular events rose with an increase in the number of risk factors $(\mathrm{P}<0.0001)$.
\end{abstract}

Conclusions: In unoperated patients with asymptomatic AS, the presence of coronary artery disease and increased global left ventricular afterload may be associated with a poor prognosis. (Circ $J$ 2016; 80: 519-525)

Key Words: Aortic stenosis; Coronary artery disease; Echocardiography; Valve disease surgery; Valvular heart disease

$\mathbf{I}$ is known that patients with symptomatic aortic stenosis (AS) have a high mortality rate and require prompt aortic valve replacement (AVR). ${ }^{1}$ In contrast, patients with asymptomatic AS have a benign prognosis and cardiovascular events are generally preceded by the development of significant symptoms. ${ }^{2-4}$ Although management of asymptomatic AS remains controversial, ${ }^{5,6}$ previous reports showed that selected patients with asymptomatic AS may benefit from AVR. ${ }^{7-11}$ Therefore, the current ACC/AHA guideline published in 2014 considers surgery as a reasonable strategy in asymptomatic patients with left ventricular ejection fraction (LVEF) $<50 \%$, very severe AS, abnormal exercise stress testing and rapid disease progression; and in patients undergoing other cardiac surgery. ${ }^{1}$ However, the covariates of cardiovascular events in unoperated patients with asymptomatic AS have not been adequately evaluated. In addition, despite the fact that an ethnic influence on the risk of AS has been proposed, ${ }^{12}$ there is a paucity of Japanese studies regarding the clinical outcomes of unoperated asymptomatic patients with severe AS.
The present study aimed to identify these covariates in a Japanese population of unoperated patients with asymptomatic severe AS.

\section{Methods}

\section{Study Population}

In this retrospective study, a total of 230 patients with asymptomatic severe AS recorded in an echocardiographic database at Juntendo University Hospital were consecutively enrolled between August 2000 and August 2012. Severe AS was defined as a peak transaortic velocity $(\mathrm{Vp})$ of $>4.0 \mathrm{~m} / \mathrm{s}$ or an aortic valve area $(\mathrm{AVA})<1.0 \mathrm{~cm}^{2}$ with normal $\mathrm{LV}$ function (LVEF $\geq 50 \%) .{ }^{1}$ When AVA was $<1.0 \mathrm{~cm}^{2}$ and there was LV dysfunction ( $\mathrm{LVEF}<50 \%$ ), severe AS was determined by the presence of severe leaflet calcification or congenital stenosis. ${ }^{1}$ All patients met the following specific inclusion criteria: age $\geq 20$ years, absence of symptoms, and no more than mild associated cardiac valve lesions. Symptoms of AS were defined as a

Received August 9, 2015; revised manuscript received November 18, 2015; accepted November 26, 2015; released online December 24, 2015 Time for primary review: 11 days

Department of Cardiology, Juntendo University School of Medicine, Tokyo (K.S., M.D., T.K., S.M., R.M.-I., M.M., S.-J.C., K.M., H.D.); Heart Center, Tokyo Bay Urayasu/Ichikawa Medical Center, Urayasu (K.S., H.W.), Japan; and Department of Internal Medicine, School of Medicine, College of Medicine, Taipei Medical University, Taipei (S.-J.C.), Taiwan

Mailing address: Masao Daimon, MD, Department of Cardiology, Juntendo University School of Medicine, 2-1-1 Hongo, Bunkyo-ku, Tokyo 113-8421, Japan. E-mail: daimon@muf.biglobe.ne.jp

ISSN-1346-9843 doi:10.1253/circj.CJ-15-0876

All rights are reserved to the Japanese Circulation Society. For permissions, please e-mail: cj@j-circ.or.jp 


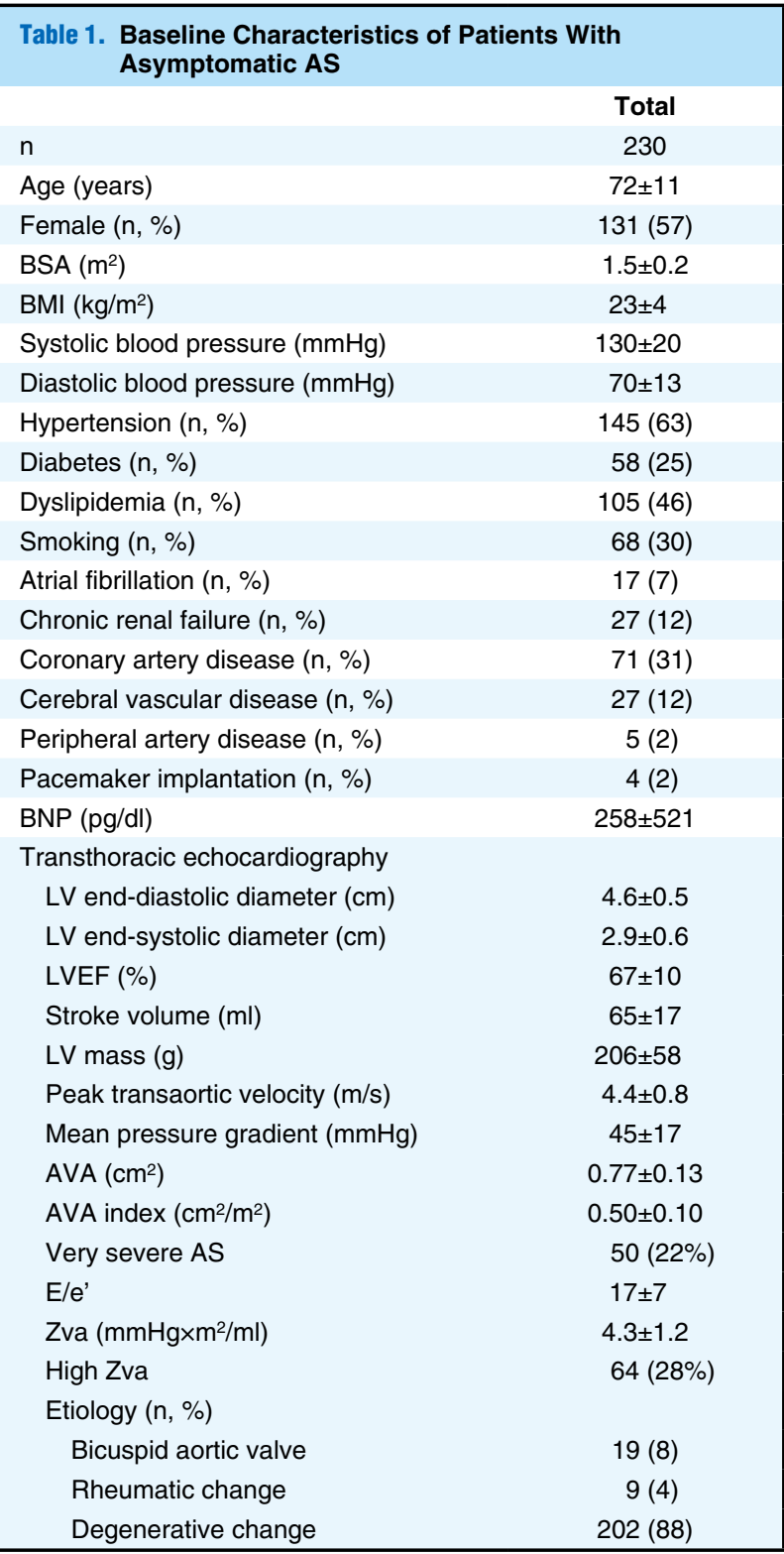

${ }^{*} \mathrm{P}<0.05$ vs. AVR group. AS, aortic stenosis; AVA, aortic valve area; AVR, aortic valve replacement; BSA, body surface area; BMI, body mass index; BNP, B-type natriuretic peptide; LV, left ventricular; Zva, valvulo-arterial impedance.

history of angina, dyspnea, syncope, presyncope or congestive heart failure reported at the time of the initial clinical and echocardiographic evaluations. ${ }^{4}$ Patients with fatigue or mild dyspnea occurring with maximal exertion were not excluded because of the lack of specificity of these symptoms. ${ }^{4}$ Patients with a past history of myocardial infarction and surgical AVR were also excluded. At study entry, clinical data, including coronary artery disease (CAD), which was defined as at least 1 epicardial artery with at least $50 \%$ stenosis or a history of percutaneous coronary intervention, ${ }^{13}$ were retrieved from the hospital database. This study was approved by the institutional review boards and all patients gave written informed consent.

\section{Echocardiographic Study}

All patients underwent comprehensive transthoracic echocardiography (TTE) that included 2D and Doppler echocardiog- raphy performed by an experienced sonographer or cardiologist using commercially available equipment. Follow-up TTE was performed at 1, 3 and 5 years after baseline TTE. Vp and mean transaortic pressure gradient (MPG) were derived from transaortic flow recorded with continuous-wave Doppler using a multi-window approach. AVA was calculated by the continuity equation, and the AVA index was calculated as AVA divided by body surface area (BSA). Both Vp and AVA were measured in all the patients. Very severe AS was defined as $\mathrm{Vp}>5.0 \mathrm{~m} / \mathrm{s}, \mathrm{MPG}>60 \mathrm{mmHg}$, and AVA $<0.60 \mathrm{~cm}^{2} .{ }^{14}$ The LV end-diastolic volume (EDV), end-systolic volume (ESV) and stroke volume were measured by Simpson's biplane method using 2D images obtained from both the apical 4- and 2-chamber views. LVEF was calculated by the following equation: $100 \times($ LVEDV-LVESV)/LVEDV. LV mass was calculated using diastolic measurements of LV internal diameter (ID) and posterior wall thickness (PWT) on 2D echocardiography according to the formula recommended by the American Society of Echocardiography: LV mass $(\mathrm{g})=0.8 \times\{1.04 \times[(\mathrm{IVST}+$ LVID+LVPWT $\left.)^{3}-(\text { LVID) })^{3}\right\}+6 \mathrm{~g}$ (where IVST is interventricular septal wall thickness). ${ }^{15}$ For assessing diastolic function, pulsed-wave Doppler examination of mitral inflow and tissue Doppler imaging of mitral annular motion at the septum were also performed. Peak velocity of early diastolic flow (E) was measured from pulsed-wave Doppler examination of mitral inflow. Early diastolic velocities at the septal mitral annulus (e') were measured from tissue Doppler imaging. The ratio of mitral E to e' (E/e') was calculated as an index of LV filling pressure. ${ }^{16}$

\section{Valvulo-Arterial Impedance (Zva)}

To estimate a global LV hemodynamic afterload, we calculated the valvulo-arterial impedance (Zva): $\mathrm{Zva}=(\mathrm{SAP}+\mathrm{MPG}) /$ $\mathrm{SVi}$, where SAP is the systolic arterial pressure and SVi is the stroke volume index (stroke volume divided by BSA), ${ }^{9,17,18}$ Hence, Zva theoretically accounts for the effects of both AS and systemic arterial compliance that oppose ventricular ejection. ${ }^{17} \mathrm{Zva}$ was considered to be high if $\geq 4.9 \mathrm{mmHg} \times \mathrm{m}^{2} / \mathrm{ml}$, according to previous reports..$^{19,20}$

\section{Follow-up and Clinical Outcomes}

Follow-up information about the development of symptoms, subsequent AVR, hospitalization because of cardiovascular events, and cardiovascular death was obtained by reviewing inpatient records, records at outpatient clinics, interviews with patients, and questionnaires mailed to all patients. Deaths were classified as either cardiovascular or noncardiovascular. Death occurring without explanation was considered as cardiovascular. The primary clinical endpoint for the present study was a cardiovascular event, which was defined as cardiovascular death or cardiovascular hospitalization. The secondary clinical endpoint was AVR.

\section{Statistical Analysis}

Data are presented as mean \pm standard deviation for continuous variables, or as number with percentage for categorical variables. Differences between groups were analyzed by t-test or Mann-Whitney U test for continuous variables, and by chisquare test or Fisher's exact probability test for categorical variables, as appropriate. To identify covariates of cardiovascular events, multivariate Cox proportional hazards regression analysis was used to identify the covariates of clinical endpoints among the baseline clinical and echocardiographic variables. Any variable with a $\mathrm{P}$ value $<0.10$ in the univariate analysis was included in the multivariate analysis. The 


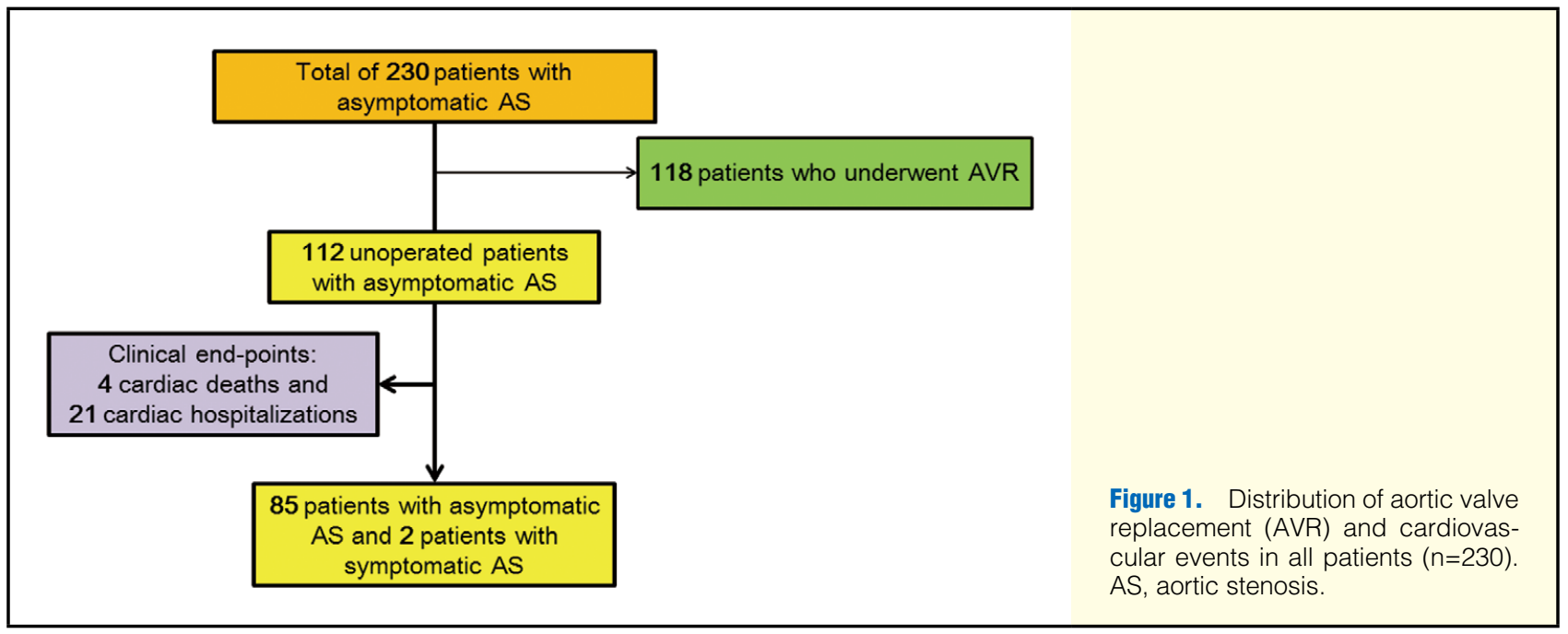

Kaplan-Meier method was used for cumulative survival analysis, with the log-rank test for assessing statistical differences between curves. Two-tailed P-values $<0.05$ were considered statistically significant. All statistical analyses were performed using SPSS 21.0 software (SPSS Inc, Chicago, IL, USA).

\section{Results}

\section{Patients Characteristics}

Baseline characteristics and echocardiographic data are outlined in Table 1. The mean age of the patients was $72 \pm 11$ years (range, 20-95 years). The mean LVEF, Vp and AVA were $67 \pm 10 \%, 4.4 \pm 0.8 \mathrm{~m} / \mathrm{s}$ and $0.77 \pm 0.13 \mathrm{~cm}^{2}$, respectively; $57 \%(n=131)$ of the patients were females. The study population included patients with CAD $(31 \%, \mathrm{n}=71)$, very severe AS $(22 \%, \mathrm{n}=50)$ and high Zva $(28 \%, \mathrm{n}=64)$.

\section{Clinical Outcomes}

Follow-up information was available for all 230 patients. The mean follow-up time was 33 \pm 31 months (range: 0-144 months). Among the 230 patients enrolled, total clinical events (cardiovascular event and AVR) occurred in 143 patients. A cardiovascular event occurred in 25 patients, comprising 4 cardiovascular deaths and 21 cardiovascular hospitalizations. The deaths were 3 from congestive heart failure and 1 from multiple embolism caused by atrial fibrillation. Hospitalization was for congestive heart failure $(n=15)$ and ischemic heart attack $(n=6)$. A total of 118 patients underwent AVR during follow-up because of the development of symptoms, LV dysfunction, or a rapid decrease in AVA; 2 patients developed AS symptoms but did not undergo subsequent AVR. In the multivariate analysis, the following significant covariates of total clinical events remained in the final model: MPG [hazard ratio (HR): 1.04, 95\% confidence interval (CI): 1.006-1.074, $\mathrm{P}<0.05$ ] and AVA (HR: 0.11, 95\% CI: 0.014-0.929, P<0.05).

The study patients were divided into 2 groups based on AVR after study enrollment: non-AVR $(\mathrm{n}=112)$, and AVR $(\mathrm{n}=118)$ (Figure 1). The non-AVR group served as the unoperated patients in this study as in previous studies. ${ }^{21,22}$ In the non-AVR group, 85 patients $(76 \%)$ remained free of a clinical event after a follow-up of $31 \pm 26$ months. The 1-year, 3-year, and 5-year event-free survival in the unoperated patients with asymptomatic AS was $87 \pm 3 \%, 77 \pm 5 \%$, and $60 \pm 9 \%$, respectively.
Covariates of Cardiovascular Events in the Non-AVR Group Table 2 compares the baseline characteristics of the non-AVR group with and without cardiovascular events. In the multivariate analysis, systolic blood pressure, CAD, AVA, and high Zva (all $\mathrm{P}<0.10$ ) were included in the initial step of the modelbuilding process. Only the following significant covariates remained in the final model: CAD (HR: 3.62, 95\% CI: $1.585-$ 8.245, $\mathrm{P}<0.01)$ and high Zva (HR: 3.08, 95\% CI: 1.261-7.532, $\mathrm{P}<0.05$ ) (Table 3).

In the non-AVR group, 44 patients $(39 \%)$ had 1 risk factor (CAD: $n=22$; high Zva: $n=22$ ) and 11 patients (10\%) had 2 risk factors. The relative risk of cardiovascular events rose with an increase in the number of risk factors $(\mathrm{P}<0.0001)$ (Figure 2). At 3 years, the probability of remaining free of cardiovascular events was $93 \pm 4 \%$ in the patients with no risk factors, $75 \pm 10 \%$ in the patients with high Zva as their only risk factor, $72 \pm 11 \%$ in the patients with CAD as their only risk factor and $20 \pm 17 \%$ in the patients with both risk factors.

\section{Serial TTE Data}

Of the 112 unoperated patients with asymptomatic AS, 1-year, 3-year, and 5-year follow-up TTE data were available for 52 patients (46\%), 37 patients $(33 \%)$ and 16 patients (14\%), respectively (Table 4). There were no significant differences in LVEF, LVESV, LV mass and LV mass index at 1, 3 and 5 years of follow-up compared with baseline values. The mean $\mathrm{Vp}$ and mean MPG were significantly increased at 1-year $(\mathrm{P}<0.01)$, 3-year $(\mathrm{P}<0.001)$ and 5-year follow-up $(\mathrm{P}<0.001)$. AVA at 5 years of follow-up $(\mathrm{P}<0.05)$ was significantly less than the baseline value, although the mean AVA at 1 and 3 years of follow-up did not change.

\section{Discussion}

The main achievement of the present study was the successful identification of the independent covariates of cardiovascular events in unoperated patients with asymptomatic AS: CAD (HR: 3.62, 95\% CI: $1.585-8.245, \mathrm{P}<0.01)$ and high Zva (HR: 3.08 , 95\% CI: $1.261-7.532, \mathrm{P}<0.05)$. The relative risk of cardiovascular events rose with an increase in the number of risk factors $(\mathrm{P}<0.0001)$. 


\begin{tabular}{|c|c|c|c|}
\hline & $\begin{array}{l}\text { Cardiovascular event } \\
(n=25)\end{array}$ & $\begin{array}{l}\text { No cardiovascular event } \\
\qquad(n=87)\end{array}$ & $P$ value \\
\hline Follow-up period $(\mathrm{m})$ & $20 \pm 21$ & $31 \pm 26$ & \\
\hline Age (years) & $73 \pm 9$ & $72 \pm 13$ & 0.7 \\
\hline Female (n, \%) & $8(32)$ & $51(59)$ & 0.2 \\
\hline $\operatorname{BSA}\left(m^{2}\right)$ & $1.6 \pm 0.2$ & $1.5 \pm 0.2$ & 0.3 \\
\hline $\mathrm{BMI}\left(\mathrm{kg} / \mathrm{m}^{2}\right)$ & $23 \pm 3$ & $23 \pm 4$ & 0.6 \\
\hline Systolic blood pressure $(\mathrm{mmHg})$ & $140 \pm 25$ & $128 \pm 18$ & $<0.05$ \\
\hline Hypertension (n, \%) & $18(72)$ & $55(63)$ & 0.5 \\
\hline Diabetes (n, \%) & $7(28)$ & $27(31)$ & 0.9 \\
\hline Dyslipidemia (n, \%) & $12(48)$ & $39(45)$ & 0.8 \\
\hline Smoking (n, \%) & $11(44)$ & $22(25)$ & 0.12 \\
\hline Atrial fibrillation $(n, \%)$ & $4(16)$ & $6(7)$ & 0.2 \\
\hline Chronic renal failure $(\mathrm{n}, \%)$ & $4(16)$ & $10(11)$ & 0.5 \\
\hline Coronary artery disease $(n, \%)$ & $13(52)$ & $20(23)$ & $<0.05$ \\
\hline Cerebral vascular disease $(n, \%)$ & $5(20)$ & $13(15)$ & 0.5 \\
\hline Peripheral artery disease $(n, \%)$ & $2(8)$ & $1(1)$ & 0.13 \\
\hline Pacemaker implantation (n, \%) & $0(0)$ & $2(2)$ & 0.9 \\
\hline BNP (pg/dl) & $143 \pm 124$ & $234 \pm 543$ & 0.4 \\
\hline LV end-diastolic diameter (cm) & $4.6 \pm 0.7$ & $4.6 \pm 0.5$ & 0.9 \\
\hline LV end-systolic diameter (cm) & $3.0 \pm 0.7$ & $2.8 \pm 0.5$ & 0.4 \\
\hline LV ejection fraction (\%) & $64 \pm 12$ & $69 \pm 8$ & 0.2 \\
\hline Stroke volume (ml) & $63 \pm 17$ & $68 \pm 18$ & 0.18 \\
\hline LV mass $(\mathrm{g})$ & $204 \pm 62$ & $198 \pm 53$ & 0.8 \\
\hline Peak transaortic velocity $(\mathrm{m} / \mathrm{s})$ & $4.0 \pm 0.9$ & $4.1 \pm 0.6$ & 0.9 \\
\hline Mean pressure gradient $(\mathrm{mmHg})$ & $39 \pm 14$ & $39 \pm 13$ & 0.9 \\
\hline $\operatorname{AVA}\left(\mathrm{cm}^{2}\right)$ & $0.78 \pm 0.11$ & $0.83 \pm 0.10$ & $<0.05$ \\
\hline AVA index $\left(\mathrm{cm}^{2} / \mathrm{m}^{2}\right)$ & $0.50 \pm 0.09$ & $0.55 \pm 0.08$ & $<0.05$ \\
\hline Very severe AS & $3(12 \%)$ & $7(8 \%)$ & 0.5 \\
\hline$E / e^{\prime}$ & $17 \pm 7$ & $17 \pm 8$ & 0.8 \\
\hline Zva $\left(\mathrm{mmHg} \times \mathrm{m}^{2} / \mathrm{ml}\right)$ & $4.8 \pm 1.2$ & $4.0 \pm 1.3$ & $<0.05$ \\
\hline High Zva & $14(56 \%)$ & $19(22 \%)$ & $<0.01$ \\
\hline Etiology (n, \%) & & & 0.4 \\
\hline Bicuspid aortic valve & $0(0)$ & $5(6)$ & \\
\hline Rheumatic disease & $1(4)$ & $5(6)$ & \\
\hline Degenerative disease & $24(96)$ & $77(88)$ & \\
\hline
\end{tabular}

${ }^{*} \mathrm{P}<0.05$ vs. AVR group. Abbreviations as in Table 1.

\begin{tabular}{|lccc|}
\hline \multicolumn{3}{|c|}{ Table 3. Results of Multivariate Analysis to Determine the Covariates of Cardiovascular Events in } \\
Unoperated Patients With Asymptomatic AS \\
Variable & HR & $95 \%$ Cl & P value \\
Systolic blood pressure & 1.01 & $0.992-1.030$ & 0.26 \\
Coronary artery disease & 3.62 & $1.585-8.245$ & $<0.01$ \\
Aortic valve area & 0.05 & $0.001-2.207$ & 0.12 \\
High Zva & 3.08 & $1.261-7.532$ & $<0.05$ \\
\hline
\end{tabular}

$\mathrm{Cl}$, confidence interval; $\mathrm{HR}$, hazard ratio. Other abbreviations as in Table 1.

\section{Covariates of Cardiovascular Event in Unoperated Patients With Asymptomatic AS}

It is well known that there is overlap in the clinical factors traditionally associated with atherosclerosis and AS. ${ }^{23}$ Thus, CAD is the most common comorbidity that influences outcomes after AVR for symptomatic AS. ${ }^{13,24}$ In fact, according to a large-scale Swedish registry, $41 \%$ of patients aged $61-70$ years, and $51 \%$ of patients aged $\geq 71$ years had significant $\mathrm{CAD}$ at the time of surgical AVR. ${ }^{24}$ In contrast, there is little information that identifies CAD as a covariate of cardiovascular events in unoperated patients with asymptomatic AS. Carstensen and colleagues demonstrated that subclinical CAD in asymptomatic AS was associated with global and regional longitudinal dysfunction. ${ }^{25}$ Moreover, some previous studies 


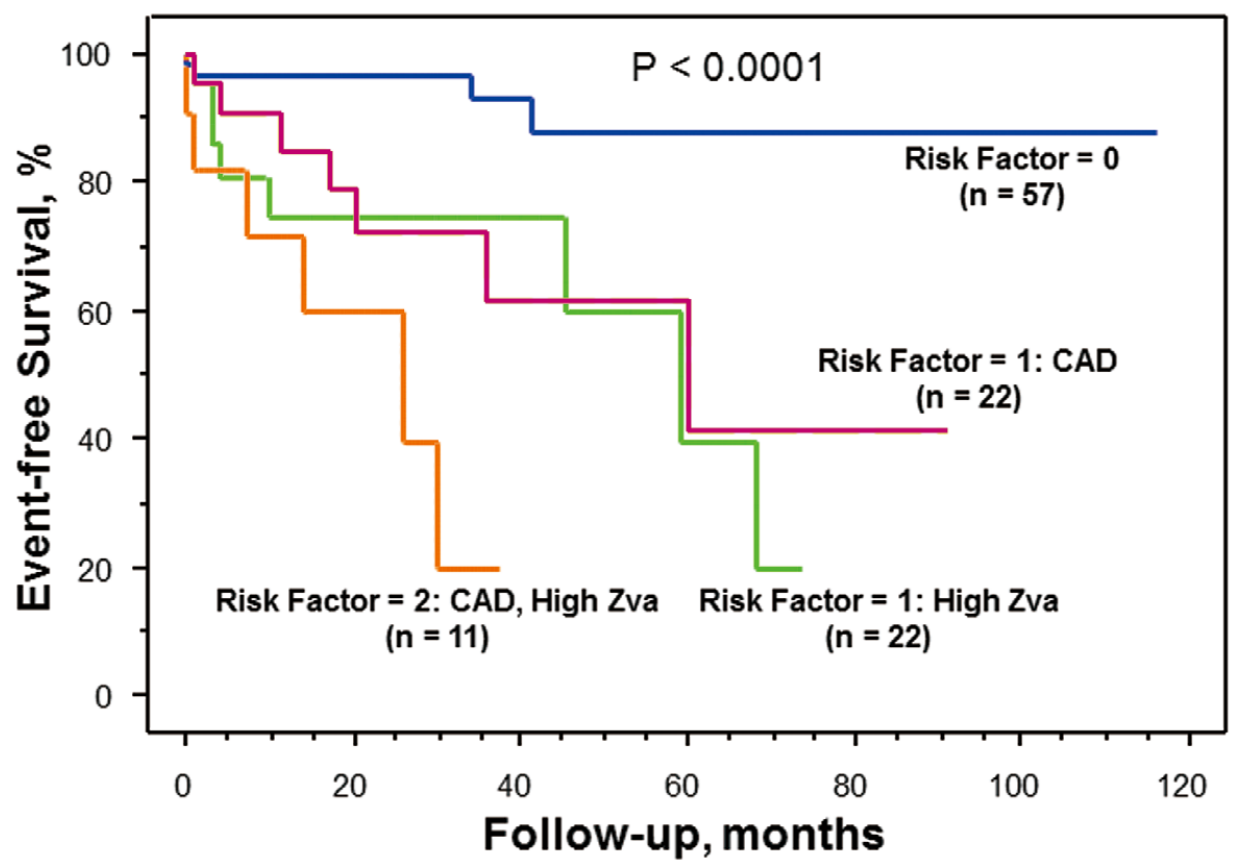

Figure 2. Kaplan-Meier event-free survival curves in the non-AVR group $(n=112)$ according to the cumulative number of risk factors, such as a past history of coronary artery disease (CAD) and high valvulo-arterial impedance (Zva). AVR, aortic valve replacement.

\begin{tabular}{|lcccc|}
\hline \multicolumn{4}{|l}{ Table 4. Serial Transthoracic Echocardiographic Data in Unoperated Patients With Asymptomatic AS } \\
$\mathrm{n}$ & Baseline & $\mathbf{1}$ year & $\mathbf{3}$ years & $\mathbf{5}$ years \\
Follow-up (months) & 112 & 52 & 37 & 16 \\
LV ejection fraction (\%) & & $13 \pm 3$ & $34 \pm 7$ & $61 \pm 10$ \\
LV end-diastolic volume (ml) & $68 \pm 9$ & $69 \pm 7$ & $68 \pm 8$ & $66 \pm 6$ \\
LV end-systolic volume (ml) & $98 \pm 27$ & $94 \pm 22^{*}$ & $96 \pm 26^{*}$ & $97 \pm 22$ \\
LV mass $(\mathrm{g})$ & $31 \pm 16$ & $30 \pm 11$ & $30 \pm 14$ & $39 \pm 26$ \\
LV mass index $\left(\mathrm{g} / \mathrm{m}^{2}\right)$ & $199 \pm 55$ & $187 \pm 51$ & $186 \pm 54$ & $211 \pm 67$ \\
E/e' & $130 \pm 35$ & $122 \pm 32$ & $121 \pm 33$ & $140 \pm 43$ \\
Aortic valve area $\left(\mathrm{cm}^{2}\right)$ & $17 \pm 8(\mathrm{n}=84)$ & $15 \pm 6(\mathrm{n}=35)$ & $15 \pm 7(\mathrm{n}=32)$ & $18 \pm 10(\mathrm{n}=12)$ \\
Peak transaortic velocity $(\mathrm{m} / \mathrm{s})$ & $0.82 \pm 0.20$ & $0.88 \pm 0.20$ & $0.82 \pm 0.18$ & $0.71 \pm 0.14^{\star}$ \\
Mean transaortic pressure gradient $(\mathrm{mmHg})$ & $4.1 \pm 0.7$ & $4.3 \pm 0.6^{* *}$ & $4.5 \pm 0.7^{* * *}$ & $4.9 \pm 0.7^{* * *}$ \\
\hline
\end{tabular}

Comparison with baseline data: ${ }^{*} \mathrm{P}<0.05,{ }^{* \star} \mathrm{P}<0.01$, and ${ }^{* *} \mathrm{P}<0.001$. Abbreviations as in Table 1.

reported that longitudinal deformation deteriorated with progressive AS. ${ }^{26-28}$ Therefore, myocardial damage caused by AS and CAD might lead to earlier cardiovascular events compared with isolated AS, even in asymptomatic patients. We also found first that Zva was an independent determinant of clinical outcome in unoperated, asymptomatic severe AS. Previous studies reported that Zva, a surrogate of global LV hemodynamic afterload, was associated with clinical outcome in asymptomatic AS, although the majority of events in those patients included death after AVR and a clinical need for AVR as well as the development of symptoms and cardiovascular death.9,17,19 Hachicha and colleagues reported that Zva $>5.5 \mathrm{mmHg} \times \mathrm{m}^{2} / \mathrm{ml}$ was associated with a 2.6 -fold increase in the risk of death in patients with symptomatic or asymptomatic AS. ${ }^{17}$ Additionally, a report by Lancellotti and colleagues demonstrated that $\mathrm{Zva} \geq 4.9 \mathrm{mmHg} \times \mathrm{m}^{2} / \mathrm{ml}$ was the best cut-off value to discriminate between asymptomatic AS patients with and without cardiovascular events. ${ }^{19}$ That same study also reported that prolonged high global LV afterload can exceed the limit of LV compensatory mechanisms and lead to an intrinsic impairment of myocardial function. ${ }^{19}$ Therefore, increased global LV afterload may be associated with early cardiovascular events, such as cardiovascular death and congestive heart failure, even in asymptomatic AS patients.

However, an earlier study by Dal-Bianco and colleagues ${ }^{29}$ reported that referral for AVR might have been confounded 
by the primary physician's treatment bias. Therefore, clinical outcome including AVR was an important limitation in previous studies. ${ }^{9,17,19}$ Furthermore, AVR that is performed on the basis of AS severity has a critical effect on the covariates of total clinical events, including AVR. Consequently, MPG and AVA were identified as the covariates of total clinical events in the present study. Thus, we also used objective clinical endpoints that excluded AVR in order to identify the risk factors that predict cardiovascular events in unoperated patients with asymptomatic AS.

\section{Clinical Outcome in Patients With Asymptomatic AS Without AVR}

Brown and colleagues showed that the 10-year survival was only $33 \%$ in AS patients who remained asymptomatic and did not undergo AVR. ${ }^{8}$ Furthermore, a study by Pai and colleagues demonstrated that patients not undergoing AVR for asymptomatic AS had a 1-year, 2-year and 5-year survival of $67 \%, 56 \%$ and $38 \%$, respectively. ${ }^{7}$ In contrast, the clinical outcomes in the present study, which included cardiovascular hospitalization as well as cardiovascular death, were better than those reported by Pai et al. Compared with the patients in that study $(\mathrm{n}=239$, female $46 \%),{ }^{7}$ the present patients $(\mathrm{n}=112$, female $53 \%)$ had a larger mean AVA $\left(0.82 \mathrm{~cm}^{2}\right.$ vs. $\left.0.72 \mathrm{~cm}^{2}\right)$ and a higher mean LVEF ( $68 \%$ vs. $57 \%$ ). Therefore, the discrepancy in clinical outcomes might have been caused by differences in the study populations.

\section{Serial TTE Changes in Unoperated Patients With Asymptomatic AS}

The present study demonstrated significant progression of $\mathrm{Vp}$ and MPG in unoperated patients with asymptomatic AS. Although there were no significant differences in AVA between baseline and 1 or 3 years of follow-up, AVA at 5 years was smaller than at baseline. A study by Otto and colleagues ${ }^{2}$ reported that the overall rate of increase in AS severity is predictable with an average annual increase in $\mathrm{Vp}$ of approximately $0.3 \mathrm{~m} / \mathrm{s}$ and a decrease in AVA of approximately $0.1 \mathrm{~cm}^{2}$. Nistri and colleagues demonstrated that the average increase in $\mathrm{Vp}$ was $0.26 \pm 0.32 \mathrm{~m} \cdot \mathrm{s}^{-1} \cdot$ year $^{-1}$ with great individual variability in hemodynamic progression. ${ }^{30}$ The present study results were consistent with those reports. ${ }^{2,30}$ There were few changes over time in LV geometry, mass, and systolic or diastolic function, which is also consistent with a previous study. ${ }^{2}$

\section{Clinical Implications}

A study by Beach and colleagues ${ }^{13}$ showed that patients with AS and CAD had worse short- and long-term prognoses and more postoperative morbidity than those with isolated AS. However, patients in that study who underwent AVR and coronary artery bypass graft for AS and CAD without evidence of myocardial damage had outcomes that were equivalent to propensity-matched isolated AS patients who underwent AVR. ${ }^{13}$ In addition, the present study demonstrated that CAD was an independent risk factor for cardiovascular events in unoperated patients with asymptomatic AS. Therefore, asymptomatic patients with severe $\mathrm{AS}$ and $\mathrm{CAD}$ may need to undergo an early aortic valve intervention before myocardial damage occurs. Similarly, asymptomatic patients with severe AS and increased Zva may potentially benefit from an early aortic valve intervention. Even if an early intervention is not indicated in patients with asymptomatic AS, medical therapy for LV ischemia and global LV afterload reduction may be beneficial. ${ }^{31}$

\section{Study Limitations}

First, patients who underwent AVR were excluded retrospectively in the present observational study of unoperated AS. Thus, selection bias may influence the clinical outcome of the unoperated patients. Further prospective study is required to clarify how Zva and CAD truly affect the natural history of unoperated AS. Second, the number of asymptomatic AS patients with cardiovascular events was low. However, the Cox proportional hazards model generated valid $\mathrm{P}$ values and CIs for the 2 significant risk factors because there were 25 cardiovascular events among 112 unoperated patients with asymptomatic AS. Third, we did not assess myocardial ischemia using stress echocardiography or nuclear imaging in asymptomatic patients with AS or CAD. ${ }^{19,22,29}$ We performed coronary angiography only in the patients who had suspected CAD by ECG or TTE. Fourth, stroke volume was calculated by the Simpson's biplane method. A previous report demonstrated no significant difference in stroke volume between by the LV outflow Doppler method and Simpson's biplane method $(\mathrm{P}=1.000) .{ }^{32}$ Fifth, the follow-up rates of TTE were low in this study. In particular, echocardiography might not be performed in patients with less severe AS, which might influence echocardiographic measurements during the follow-up period.

Our study patients with asymptomatic AS underwent echocardiography because they had a cardiac murmur on auscultation or abnormal ECG, or because they had been referred for suspected AS or other cardiovascular disease. These reasons why asymptomatic patients underwent echocardiography could be a selection bias of the study population. Unfortunately, details of this information were not available for all patients.

\section{Conclusions}

In unoperated patients with asymptomatic AS, the presence of $\mathrm{CAD}$ and the magnitude of global LV afterload may be associated with a poor prognosis. Furthermore, the relative risk of cardiovascular events rose with an increase in the number of risk factors.

\section{Funding Sources}

This work was partially supported by a Grant-in-Aid for Scientific Research C (24500554) from the Japan Society for the Promotion of Science (M.D.).

\section{References}

1. Nishimura RA, Otto CM, Bonow RO, Carabello BA, Erwin JP 3rd, Guyton RA, et al; ACC/AHA Task Force Members. 2014 AHA/ ACC Guideline for the Management of Patients with Valvular Heart Disease: A report of the American College of Cardiology/American Heart Association Task Force on Practice Guidelines. J Am Coll Cardiol 2014; 63: e57-e185, doi:10.1016/j.jacc.2014.02.536.

2. Otto CM, Burwash IG, Legget ME, Munt BI, Fujioka M, Healy NL, et al. Prospective study of asymptomatic valvular aortic stenosis: Clinical, echocardiographic, and exercise predictors of outcome. Circulation 1997; 95: 2262-2270.

3. Rosenhek R, Binder T, Porenta G, Lang I, Christ G, Schemper M, et al. Predictors of outcome in severe, asymptomatic aortic stenosis. $N$ Engl J Med 2000; 343: 611-617.

4. Pellikka PA, Sarano ME, Nishimura RA, Malouf JF, Bailey KR, Scott CG, et al. Outcome of 622 adults with asymptomatic, hemodynamically significant aortic stenosis during prolonged follow-up. Circulation 2005; 111: 3290-3295.

5. Carabello BA. Should severe aortic stenosis be operated on before symptom onset?: Aortic valve replacement should be operated on before symptom onset. Circulation 2012; 126: 112-117.

6. Shah PK. Should severe aortic stenosis be operated on before symptom onset?: Severe aortic stenosis should not be operated on before symptom onset. Circulation 2012; 126: 118-125. 
7. Pai RG, Kapoor N, Bansal RC, Varadarajan P. Malignant natural history of asymptomatic severe aortic stenosis: Benefit of aortic valve replacement. Ann Thorac Surg 2006; 82: 2116-2122.

8. Brown ML, Pellikka PA, Schaff HV, Scott CG, Mullany CJ, Sundt $\mathrm{TM}$, et al. The benefits of early valve replacement in asymptomatic patients with severe aortic stenosis. J Thorac Cardiovasc Surg 2008; 135: $308-315$.

9. Hachicha Z, Dumesnil JG, Pibarot P. Usefulness of the valvuloarterial impedance to predict adverse outcome in asymptomatic aortic stenosis. J Am Coll Cardiol 2009; 54: 1003-1011.

10. Monin JL, Lancellotti P, Monchi M, Lim P, Weiss E, Piérard L, et al. Risk score for predicting outcome in patients with asymptomatic aortic stenosis. Circulation 2009; 120: 69-75.

11. Le Tourneau T, Pellikka PA, Brown ML, Malouf JF, Mahoney DW, Schaff HV, et al. Clinical outcome of asymptomatic severe aortic stenosis with medical and surgical management: Importance of STS score at diagnosis. Ann Thorac Surg 2010; 90: 1876-1883.

12. Patel DK, Green KD, Fudim M, Harrell FE, Wang TJ, Robbins MA. Racial differences in the prevalence of severe aortic stenosis. $J \mathrm{Am}$ Heart Assoc 2014; 3: e000879, doi:10.1161/JAHA.114.000879.

13. Beach JM, Mihaljevic T, Svensson LG, Rajeswaran J, Marwick T, Griffin B, et al. Coronary artery disease and outcomes of aortic valve replacement for severe aortic stenosis. J Am Coll Cardiol 2013; 61: 837-848.

14. Rosenhek R, Zilberszac R, Schemper M, Czerny M, Mundigler G, Graf S, et al. Natural history of very severe aortic stenosis. Circulation 2010; 121: 151-156.

15. Lang RM, Bierig M, Devereux RB, Flachskampf FA, Foster E, Pellikka PA, et al; Chamber Quantification Writing Group; American Society of Echocardiography's Guidelines and Standards Committee; European Association of Echocardiography. Recommendations for chamber quantification: A report from the American Society of Echocardiography's Guidelines and Standards Committee and the Chamber Quantification Writing Group, developed in conjunction with the European Association of Echocardiography, a branch of the European Society of Cardiology. J Am Soc Echocardiogr 2005; 18: $1440-1463$.

16. Nagueh SF, Appleton CP, Gillebert TC, Marino PN, Oh JK, Smiseth $\mathrm{OA}$, et al. Recommendations for the evaluation of left ventricular diastolic function by echocardiography. $J$ Am Soc Echocardiogr 2009; 22: 107-133.

17. Hachicha Z, Dumesnil JG, Bogaty P, Pibarot P. Paradoxical lowflow, low-gradient severe aortic stenosis despite preserved ejection fraction is associated with higher afterload and reduced survival. Circulation 2007; 115: 2856-2864.

18. Shibayama K, Harada K, Berdejo J, Mihara H, Tanaka J, Gurudevan $\mathrm{SV}$, et al. Effect of transcatheter aortic valve replacement on the mitral valve apparatus and mitral regurgitation: Real-time threedimensional transesophageal echocardiography study. Circ Cardiovasc Imaging 2014; 7: 344-351.
19. Lancellotti P, Donal E, Magne J, Moonen M, O'Connor K, Daubert JC, et al. Risk stratification in asymptomatic moderate to severe aortic stenosis: The importance of the valvular, arterial and ventricular interplay. Heart 2010; 96: 1364-1371.

20. Lancellotti P, Donal E, Magne J, O'Connor K, Moonen ML, Cosyns $\mathrm{B}$, et al. Impact of global left ventricular afterload on left ventricular function in asymptomatic severe aortic stenosis: A two-dimensional speckle-tracking study. Eur J Echocardiogr 2010; 11: 537-543.

21. Biner S, Rafique AM, Goykhman P, Morrissey RP, Naghi J, Siegel RJ. Prognostic value of E/E' ratio in patients with unoperated severe aortic stenosis. JACC Cardiovasc Imaging 2010; 3: 899-907.

22. Roberts WC, Vowels TJ, Filardo G, Ko JM, Mathur RP, Shirani J. Natural history of unoperated aortic stenosis during a 50-year period of cardiac valve replacement. Am J Cardiol 2013; 112: 541-553.

23. Freeman RV, Otto CM. Spectrum of calcific aortic valve disease: Pathogenesis, disease progression, and treatment strategies. Circulation 2005; 111: 3316-3326.

24. Kvidal P, Bergström R, Hörte LG, Ståhle E. Observed and relative survival after aortic valve replacement. J Am Coll Cardiol 2000; 35: 747-756.

25. Carstensen HG, Larsen LH, Hassager C, Kofoed KF, Jensen JS, Mogelvang R. Association of ischemic heart disease to global and regional longitudinal strain in asymptomatic aortic stenosis. Int $J$ Cardiovasc Imaging 2015; 31: 485-495.

26. Yingchoncharoen T, Gibby C, Rodriguez LL, Grimm RA, Marwick $\mathrm{TH}$. Association of myocardial deformation with outcome in asymptomatic aortic stenosis with normal ejection fraction. Circ Cardiovasc Imaging 2012; 5: 719-725.

27. Attias D, Macron L, Dreyfus J, Monin JL, Brochet E, Lepage L, et al. Relationship between longitudinal strain and symptomatic status in aortic stenosis. J Am Soc Echocardiogr 2013; 26: 868-874.

28. Sato K, Seo Y, Ishizu T, Takeuchi M, Izumo M, Suzuki K, et al. Prognostic value of global longitudinal strain in paradoxical lowflow, low-gradient severe aortic stenosis with preserved ejection fraction. Circ J 2014; 78: 2750-2759.

29. Dal-Bianco JP, Khandheria BK, Mookadam F, Gentile F, Sengupta PP. Management of asymptomatic severe aortic stenosis. J Am Coll Cardiol 2008; 52: 1279-1292.

30. Nistri S, Faggiano P, Olivotto I, Papesso B, Bordonali T, Vescovo $\mathrm{G}$, et al. Hemodynamic progression and outcome of asymptomatic aortic stenosis in primary care. Am J Cardiol 2012; 109: 718-723.

31. Yamamoto K, Yamamoto H, Takeuchi M, Kisanuki A, Akasaka T, Ohte N, et al. Risk factors for progression of degenerative aortic valve disease in the Japanese: The Japanese Aortic Stenosis Study (JASS) prospective analysis. Circ J 2015; 79: 2050-2057.

32. Silva CD, Pedro F, Deister L, Sahlén A, Manouras A, Shahgaldi K. Two-dimensional color Doppler echocardiography for left ventricular stroke volume assessment: A comparison study with three-dimensional echocardiography. Echocardiography 2012; 29: 766-772. 